\title{
Measuring the indirect costs associated with the establishment of a wind farm: An application of the contingent valuation method
}

\author{
Mario du Preez \\ Greig Menzies \\ Michael Sale \\ Stephen Hosking \\ Department of Economics, Nelson Mandela Metropolitan University
}

\begin{abstract}
Although a green energy source, the location of electrical generating wind turbines may cause a disamenity effect (negative externality). The establishment of a wind farm is known as a locally undesirable land use (LULU) and leads to the not in my backyard syndrome (NIMBY). In an application of the contingent valuation method (a survey technique which elicits individuals' preferences and measures these preferences in monetary terms) a willingness to accept a framework was used to estimate the aggregate annual compensation required to allow the construction of a wind farm near Jeffrey's Bay, South Africa. This compensation amounted to R490 695. A binary choice Logit analysis found that retirement status, concern about climate change, concern about view shed impacts and the offer amount are important predictors of voting for or against the project.
\end{abstract}

Keywords: contingent valuation method, indirect cost, wind farm

\section{Introduction}

Over the past 40 years there has been recognition of the fact that human activity has reached a scale capable of influencing our environment (Davidson, 2005). Along with diminishing sources of known fossil fuel deposits, this growing environmental awareness has led to a search for alternative sources of energy, especially clean energies. There are a number of renewable energy sources currently receiving attention on the global stage, including wind, solar, thermal, hydro, biomass and tidal power. Technologies exist that are capable of creating electricity from all of these sources. Of all the potential renewable energy sources, wind energy has experienced the greatest growth worldwide over the past few years (Yue, Liu \& Liou, 2001).

Although wind energy is a relatively well-established source of energy internationally, it has yet to penetrate the South African market, despite the potential due to South Africa's long coast line and abundant open areas. Opponents of wind energy argue that there are local negative externalities (or indirect costs) associated with the location of wind turbines, which include the potential deterioration of scenic views and the disturbing noise created by the rotation of the turbines (Warren, Lumsden, O'Dowd, \& Birnie, 2005). These externalities fall into the broad problem known as a locally undesirable land use (LULU). In turn, these locally undesir- 
able uses of land may lead to the not in my backyard syndrome (NIMBY). It is argued that this syndrome may lead to inefficient resource allocation because the costs of the negative externality are borne locally while the benefits are distributed more broadly (O'Hare, 1977). A possible solution to the problem is compensating those affected by the local externality. In a study conducted by Groothuis, Groothuis \& Whitehead (2008) a measure of the compensation required to allow wind generation windmills to be built in the mountains of Watuaga County, North Carolina, USA was estimated. The results of the study indicate that an amount of $\$ 1.90$ per month or $\$ 23$ per annum per household was required for the project to go ahead. Based on an estimated18 540 households in Watuaga County, total compensation required equalled $\$ 426,400$. These results indicate that people are willing to accept a reduction in scenic view quality due to the construction of a wind farm, provided they receive adequate compensation.

The development of a wind farm, by Genesis Eco-Energy (Pty) Ltd, in close proximity to Jeffrey's Bay, South Africa, may be viewed by some as a LULU. The project is located on the Sunnyside dairy farm approximately $5 \mathrm{~km}$ from Jeffrey's Bay on the slope of a hill north of the N2 highway connecting Port Elizabeth and Cape Town. The closest inhabited residential area is a suburb of Jeffrey's Bay called Wavecrest (Lochner et al., 2008). The selection of appropriately sized wind turbines is still under consideration. It is expected that machines of 1.8 to $2 \mathrm{MW}$ will be installed. One turbine size is expected to be used for the entire wind farm. The final choice of the size of turbine will be based on ease of erection, availability, suitability to the wind regime and flicker effects (Lochner et al., 2008). Table 1 below shows the details of the proposed project.

Table 1: Project specification

Source: Lochner et al.,(2008)

\begin{tabular}{ll}
\hline \multicolumn{1}{c}{ Characteristic } & \multicolumn{1}{c}{ Value } \\
\hline Name & Kouga Wind Energy Project \\
\hline Location & $\begin{array}{l}\text { Sunnyside Dairy Farm, Jeffrey's } \\
\text { Bay }\end{array}$ \\
\hline Installed capacity & $15 \mathrm{MW}$ \\
\hline Project life & 25 years \\
\hline $\begin{array}{l}\text { No. of turbines } \\
\text { (turbine capacity) }\end{array}$ & $8(\approx 2 \mathrm{MW})$ to $30(\approx 500 \mathrm{~kW})$ \\
\hline Area required & $20 \mathrm{ha}$ \\
\hline Turbine height & $75 \mathrm{~m}$ \\
\hline Blade length & $45 \mathrm{~m}$ \\
\hline Annual capacity factor & $30 \%$ \\
\hline Electricity production & $21462 \mathrm{MWh}$ \\
\hline $\mathrm{CO}_{2}$ off-set & 545000 tonnes \\
\hline
\end{tabular}

The wind measurement studies undertaken at the site indicate kilowatt hours ( $\mathrm{kWh}$ ) production will be relatively equally distributed both daily and seasonally (Lochner et al., 2008). The wind turbines will be connected to the local Eskom grid via a new line ( $22 \mathrm{kV}$ capacity) of approximately $500 \mathrm{~m}$ in length (maximum) which connect to the existing municipal power line of $66 \mathrm{kV}$ that passes the eastern edge of the site. Certain sections of the existing power lines may require upgrades, but this will require only installing new conductors, not an entirely new line (Lochner et al., 2008). Should the existing lines not be able to carry all of the load, it may be necessary to run a new $66 \mathrm{kV}$ line from the site to the main Eskom $132 \mathrm{kV}$ line that joins from the Melkhout substation (Lochner et al., 2008).

The aim of this study was to provide the first formal attempt to quantify the compensation required ${ }^{1}$ to overcome the NIMBY syndrome associated with the establishment of a wind farm in South Africa; the specific wind farm being the one in Jeffrey's Bay, Eastern Cape. The compensation required is estimated by means of the contingent valuation method (CVM).

\section{The contingent valuation method}

The contingent valuation method (CVM) has over time become one of the most often used non-market valuation techniques. The method employs either willingness-to-pay questions to elicit individuals' preferences for improvements in public goods or willingness-to-accept questions to elicit individuals' preferences for deteriorations in public goods (Mitchell and Carson, 1989). Willingness-to-pay is defined as the price an individual would be willing to pay to avoid the loss of an environmental service, whereas willingness-to-accept is the amount an individual would accept in compensation for the loss of an environmental service. The Blue Ribbon Panel Report to the NOAA Panel on Contingent Valuation $(\mathrm{CV})$ resolved that it is a reliable and useful technique (see Arrow et al., 1993). The report also provided guidelines for good CV practice.

One of four elicitation methods can be employed in CVM studies, namely bidding games, open ended questions, payment cards, and dichotomous choice questions. A bidding game entails suggesting higher (lower) and higher (lower) amounts to individuals until their maximum WTP or minimum WTA (a point estimate) is reached (Mitchell and Carson, 1989). An open ended question is one in which an individual is asked to state his/her maximum WTP or minimum WTA (no values are suggested in this case). The payment card method presents an individual with a range of values from which he/she is requested to select the one which contains his/her maximum WTP or minimum WTA. With the dichotomous choice format an individual is presented with a single payment/offer 
(WTP/WTA amount) to which he/she must either agree or disagree.

Once the WTP or WTA responses are collected, a limited dependent parametric model, namely the Logit model ${ }^{2}$ can be applied to estimate preference functions, which in turn, are used to calculate expected WTP or WTA values.

The economic theory underlying the application of the willingness-to-accept framework to the establishment of a wind farm can be explained as follows: assume a resident has the following utility function, utility $=\mathrm{u}(\mathrm{x}(\mathrm{q}), \mathrm{z})$, where $\mathrm{z}$ represents a consumption good and $\mathrm{x}(\mathrm{q})$ represents quality of a scenic amenity that can be affected by the presence of wind turbines. This proposition follows the widely held view that scenic quality influences the satisfaction people get from living in an area. This resident maximizes his or her utility subject to a budget constraint $y=p x+z$ (where the price of $z$ is normalized to one). Solving for the indirect utility function yields $\mathrm{v}(\mathrm{p}, \mathrm{q}, \mathrm{y})$ where $\mathrm{y}$ is income and $\mathrm{p}$ represents the price of the scenic amenity (Groothuis et al., 2008). The WTA for a reduction in the quality of the scenic view amenity can be ascertained when

$$
\mathrm{v}\left(\mathrm{p}^{\circ}, \mathrm{q}^{\circ}, \mathrm{y}\right)=\mathrm{v}\left(\mathrm{p}^{\circ}, \mathrm{q}^{1}, \mathrm{y}+\mathrm{WTA}\right)
$$

where $\mathrm{p}^{\circ}$ is the current price, $\mathrm{q}^{\circ}$ is the original amenity quality and $\mathrm{q}^{1}$ is the lowered amenity quality, and WTA is the willingness to accept welfare measure for lowering the quality of the scenic amenity (Groothuis et al., 2008). When the amenity quality is lowered (from $\mathrm{q}^{\circ}$ to $\mathrm{q}^{1}$ ) and the resident is compensated for this, the resident's total utility is unaffected. In Equation (1), WTA is not income constrained. More specifically, WTA is added to income. ${ }^{3}$

\section{Survey design}

\subsection{Questionnaire development}

The most important task in conducting a CVM study is the design of the questionnaire. With this in mind, every attempt was made to adhere to the guidelines recommended in the Arrow et al. (1993) report. These attempts are described below.

The survey was conducted via personal interviews and the pre-coded questionnaire, used as the survey instrument, was pre-tested by members of the research team. The questionnaire was subsequently refined and improved. A scenario was formulated to make the respondents aware of the effects of the proposed wind turbines. An accurate description of the project was presented to respondents and photographs of existing turbines were shown to the respondents. These photographs were pre-tested by members of the research team. The valuation question was posed as a vote on a referendum. More specifically, respondents were asked whether or not they would accept the establishment of the wind farm on the designated site in return for the specified compensation offer. Different WTA offer amounts were used, as 'it is crucial that the arbitrarily assigned sums be varied across respondents' (Cameron, 1987). The contingent valuation question in the survey was:

Suppose to compensate individuals for accepting the wind farm in their area, electricity bills would be reduced by $R \mathrm{XXX}$ each month per household. Suppose this proposal is on the next election ballot. How would you vote on this proposal?

YES/NO

The $\mathrm{R}$ amount was randomly filled in with one of 6 rand amounts (R1, R5, R15, R30, R50 and R75) ${ }^{4}$. Following the status quo approach, all 'Don't Know' responses were treated as 'No' responses (Groothuis et al., 2008).

Although it has been well documented that the WTP framework is the preferred format in CVM studies, the WTA elicitation method was employed in this study, given the perceived property rights of individuals in this particular context (Groothuis et al., 2008). It has been suggested by Inhaber (1992) that due to a reluctance to infringe on perceived property rights (based on politicians' concerns about remaining in office) the status quo becomes the default property right when choosing a project's location that will give rise to the NIMBY syndrome. WTA thus becomes the appropriate measure when individuals perceive that the status quo defines the property rights (Groothuis, et al., 2008).

A follow-up question was included in the questionnaire in of er to determine the reasons for all 'no' responses. Non-responses to the WTA question were zero.

\subsection{Data collection}

Sufficient research funds were available to allow for a sample of 180 respondents, representing $5.4 \%$ of the target population, to be interviewed face-to-face during the period January 2010 to March 2010. The sample frame consisted of residents of the Wavecrest suburb (Jeffrey's Bay) situated in close proximity to the proposed site and who would thus be directly exposed to the wind farm..$^{5}$ There are 4348 plots in Wavecrest, of which 3349 are registered as developed plots. A representative sample of this population was chosen.

The sample size for this population was determined by employing the following formula:

$$
n=
$$

where:

$\mathrm{n}=$ sample size

$\mathrm{N}=$ population size 
$e=$ level of precision

Using the formula in Equation (2), the sample size was determined with a level of precision of $7.25 \%$. This level of precision ensures a representative sample from the population, because the generally accepted level of precision for representative samples is $10 \%$ or less (Fink, 2003).

\section{Statistical results and discussion 4.1 Socio-economic, behavioural and attitudinal analysis of respondents}

Table 2 provides a summary of the socio-economic profiles of the sample of households who were interviewed as part of the questionnaire survey.

The questionnaire also included certain key questions which allowed an analysis of the respondents' behaviour and attitude towards the proposed wind farm project (see Table 3).

Table 2: Socio-economic profile of respondents

\begin{tabular}{lc}
\hline \multicolumn{1}{c}{ Variable } & Mean \\
\hline Age (years) & 59 \\
\hline Education (years) & 12.85 \\
\hline Number of children & 2.25 \\
\hline Household size & 2.73 \\
\hline Retired (\%) & 53.89 \\
\hline Employed (\%) & 30.56 \\
\hline Resident (years) & 8.95 \\
\hline Monthly electricity bill (R) & 490.37 \\
\hline Gross annual income (R) & 131889.89 \\
\hline
\end{tabular}

Table 3: Behavioural and attitudinal profile of respondents

\begin{tabular}{lc}
\hline Behaviour/attitude & \% of respondents \\
\hline Aware of project & $72.78 \%$ \\
\hline $\begin{array}{l}\text { Subscription to scientific/environmental } \\
\text { publication }\end{array}$ & $6.67 \%$ \\
\hline Member of environmental organisation & $2.22 \%$ \\
\hline Member of outdoor organisation & $5.56 \%$ \\
\hline Renewables should be government priority & $99.44 \%$ \\
\hline Concern about dependency on fossil fuels & $83.89 \%$ \\
\hline Concern about climate change & $84.44 \%$ \\
\hline Concern about wind turbines' harm to views & $20.56 \%$ \\
\hline
\end{tabular}

\subsection{An analysis of WTA responses}

Table 4 reports the number and percentage of 'yes' responses at each offer amount. At the lowest rand amounts, $86.67 \%$ indicated they would accept the offer. As can be expected, the percentage of 'yes' responses increases as the offer amount increases.

Table 4: Responses at each offer amount

\begin{tabular}{llll}
\hline Offer amount & Yes & No & $\%$ Yes \\
\hline
\end{tabular}

\begin{tabular}{lllc}
$\mathrm{R} 1$ & 26 & 4 & $86.67 \%$ \\
\hline $\mathrm{R} 5$ & 26 & 4 & $86.67 \%$ \\
\hline $\mathrm{R} 15$ & 27 & 3 & $90 \%$ \\
\hline R30 & 28 & 2 & $93.33 \%$ \\
\hline R50 & 29 & 1 & $96.67 \%$ \\
\hline R75 & 30 & 0 & $100 \%$ \\
\hline
\end{tabular}

\subsection{Statistical model of WTA}

Due to the referendum format of the WTA question where a respondent simply votes 'yes' or 'no' to a single Rand amount, the probability they would accept a given Rand amount is statistically estimated by means of a qualitative choice model such as a Logit model.

The Logit model can be expressed more formally as:

$$
\text { Probability }(\text { Yes })=1 /\left(1+e^{-\beta} x\right)
$$

where $\beta^{\prime} X_{i}=\beta_{0}+\beta_{1} X_{i}$. The $\beta$ 's are coefficients to be estimated using the Logit statistical technique and the independent variable, $\mathrm{X}_{\mathrm{i}}$, is the Rand amount the household was asked to accept. Independent (explanatory) variables could include the WTA amount only or could include the WTA amount and a combination of socio-economic, behavioural and attitudinal variables. Logit models make use of maximum likelihood criterion in estimation procedures, as opposed to the ordinary least squares criterion (Gujarati, 2003).

Fourteen independent variables were originally included in the Logit model (Dimitripoulos \& Kontolean, 2009; Groothuis et al., 2008; Ladenburg, 2008; Kondouri, Kountouris and Remoundo, 2009). These were: age of respondent, years of education of respondent, number of children, household size, whether the respondent was a retiree, whether the respondent was employed, years the respondent had been a resident in the town, average monthly electricity bill, gross annual income, awareness of the project, concern about fossil fuel dependence, concern about climate change, concern about view shed impacts and the WTA offer amount.

A complete statistical model inclusive of all the above mentioned attitudinal, behavioural and socio-economic variables was initially estimated. Following an inspection of statistically significant coefficients, a more parsimonious model (the reduced model) was estimated. The following coefficients were insignificant and were excluded from the final model: age of respondent, years of education of respondent, number of children, household size, whether the respondent was employed, years the respondent had been a resident in the town, average monthly electricity bill, gross annual income, awareness of the project and concern about fossil fuel dependence. 
Table 5: Logit regression model of probability would accept compensation

\begin{tabular}{lllc}
\hline Variable & Coefficient & z-Statistic & Median \\
\hline Constant & 0.571764 & 0.510038 & \\
\hline Retired & 1.809932 & $2.163313^{*}$ & 1 \\
\hline Concern about climate change & 2.124368 & $2.417749^{*}$ & 1 \\
\hline Concern about view impact & -4.354802 & $-4.326954^{* *}$ & 1.326606257 \\
\hline Log of offer amount & 1.800294 & $2.782895^{* *}$ & \\
\hline McFadden $\mathrm{R}^{2}$ & 0.492090 & & \\
\hline * Significant at the 0.05 level & & & \\
** Significant at the 0.01 level & & & \\
\hline
\end{tabular}

The reduced statistical model estimated was:

$$
\begin{aligned}
& {[\log (\text { yes }) /(1 \text {-yes })]=\beta_{0}+\beta_{1}(\text { RETIRED })} \\
& +\beta_{2}(\text { CLIMATE CHANGE }) \\
& +\beta_{3}(\text { VIEW IMPACT })+\beta_{4} \log (\text { OFFER })
\end{aligned}
$$

where 'yes' is the dependent variable and shows whether a person was or was not willing to accept the amount offered during the questionnaire survey. A yes vote was recorded with a 1 , and a no vote with a 0 .

In the interests of conserving space, only the reduced model with coefficients significant at the $90 \%$ level or better is displayed (see Table 5).

The statistically significant coefficients can be interpreted as follows:

- Retired: The retired variable's coefficient is statistically significant at the $5 \%$ level. The positive sign indicates that if the respondent is retired he or she would be more likely to accept the compensation offered for the project to go ahead.

- Concern about climate change: This variable's coefficient is positive and statistically significant at the $5 \%$ level. This means that if the respondent is concerned about climate change he or she would be more likkefly tho agree to accept the compensation offered for the project to go ahead.

- Concern about view impact: The coefficient of this variable is statistically significant at the $1 \%$ level and its negative sign suggests that if the respondent is concerned about the impact of the wind turbines on views, he or she would be less likely to accept the compensation offered for the project to go ahead.

- Offer amount: The positive sign of this coefficient suggests that the respondent would be more likely to vote in favour of the project at higher offer amounts. The coefficient is statistically significant at the $1 \%$ level.

\subsection{Median and total WTA estimates}

From Equation (3), Cameron (1987) provides a formula to calculate the median WTA. The formula is:

$$
\text { Median WTA }=\exp
$$

where $\beta_{1}$ is the coefficient on the offer amount and $\beta_{0}$ is the grand constant calculated as the sum of the estimated constant plus the product of the other explanatory variables times their respective median values.

Using the formula in Equation (5), median WTA per household was estimated at R12.21 per month or R146.52 per annum. To calculate the total indirect cost to the Wavecrest population of the establishment of a wind farm, the median household WTA estimate was multiplied by the number of households in Wavecrest (3349). The total monthly indirect cost associated with the project is $\mathrm{R} 40$ 891.29 , which translates into an annual figure of R490 695.48.6 The aggregate WTA estimation, however, constitutes only a partial analysis of cost. The capital, operating and maintenance costs of the wind farm project along with the indirect cost estimated in this paper need to be analyzed and compared with the total benefit (financial and environmental) estimates if adequate holistic decision-making is to take place. More specifically, the aggregate WTA estimated in this study must be viewed as only one cost input into a comprehensive social costbenefit analysis to determine the desirability of wind farms for wider society.

\section{Conclusion}

The premise of this study was that individuals who are negatively affected by the local externalities caused by wind turbines are willing to accept compensation in the form of lower electricity costs. This compensation could play a role in helping to eliminate the not in my backyard (NIMBY) syndrome. This paper estimates the aggregate WTA (compensation) for the construction of a wind farm in close proximity to Jeffrey's Bay, South Africa to be R490 695.48 per annum. The study also shows that individuals' WTA is mainly influenced by two factors, namely concerns about climate change and concerns about view shed impacts. The results suggest that individuals who are concerned about climate change have less of a NIMBY reaction to view shed impacts compared to individuals who are not as concerned about climate change. Respondents, who are retired, are more likely to vote in favour of 
wind powered electricity. The aggregate WTA estimated in this study must, however, be viewed as only one cost input into a comprehensive social cost-benefit analysis to determine the economic feasibility of wind farms for wider society.

\section{Notes:}

1. An anonymous referee pointed out that this method may not measure all the indirect costs associated with the wind farm and that additional costs may come to light once the wind farm is operational. In addition to this, an anonymous referee felt that resistance to the wind farm may grow over time and a further indirect cost would be for the operator to actively influence local perceptions.

2. The Logit model is an estimation technique for equations with dummy dependent variables (Studenmond, 2006).

3. Conversely, WTP is the amount of income an individual would give up to make him/her indifferent between the original state and the revised state. The indirect utility function is given by: $v\left(p^{\circ}, q^{\circ}, y\right)=v\left(p^{\circ}\right.$, $\left.\mathrm{q}^{1}, \mathrm{y}-\mathrm{WTP}\right)$. Accordingly, WTP is thus income constrained (i.e., $y-W T P$ ). Due to the fact that WTA is not income constrained its use as opposed to WTP may thus impart upward bias.

4. It was suggested by an anonymous referee that these values could have spread through the community. It is thus recommended that future studies of this nature include a question asking the respondent if they are aware of the survey being undertaken.

5. An anonymous referee indicated that the owners of empty stands also have status quo rights and should also be compensated.

6. An anonymous referee felt that this could be disbursed via the local municipality via a credit on the monthly account. Furthermore, it was advised by an anonymous referee that the wind farm operator should pay a premium above the indicated value.

\section{Acknowledgements}

The authors wish to thank two anonymous referees for their valuable comments as well as an anonymous referee from the ERSA for additional comments and recommendations. The financial support from the ERSA is also gratefully acknowledged.

\section{References}

Arrow, K., Solow, R., Portney, P.R, Leamer, E.E., Radner, R. and Schuman, H. (1993). Report of the NOAA Panel on Contingent Valuation. Federal Register, 58 (10), 4601 - 4614.

Cameron, T.A. (1987). A New Paradigm for Valuing Nonmarket Goods Using Referendum Data: Maximum Likelihood Estimation by Censored Logit Regression. Journal of Environmental Economics and Management, 15, 355 - 379.
Davidson, K. (2005). Will the Concept of 'Sustainable Development' Provide any Solutions for the $21^{\text {st }}$ Century. Paper presented to the Social Change in the $21^{\text {st }}$ Century Conference, Centre for Social Change Research, Queensland University of Technology.

Dimitripoulos, A., and Kontoleon, A. (2009). Assessing the Determinants of Local Acceptability of Wind-farm Investment: a Choice Experiment in the Greek Aegean Islands. Energy Policy, 37 (5), 1842 - 1854.

Duvenage, D. (2009). Personal Communication. Town Planning Department, Kouga Municipality.

Fink, A. (2003). The Survey Handbook, $2^{\text {nd }}$ Edition, California: Sage Publications.

Groothuis, P.A., Groothuis, J.D., and Whitehead, J.C. (2008). Green vs. Green: Measuring the Compensation Required to Site Electrical Generation Windmills in a Viewshed. Energy Policy 36, 1545 - 1550.

Gujarati, D.N. (2003). Basic Econometrics, $4^{\text {th }}$ Edition, New York: Mcgraw-Hill.

Inhaber, H. (1992). Of LULUs, NIMBYs and NIMTOOs. The Public Interest, 107, 52 - 64.

Kondouri, P., Kountouris, Y., and Remoundo, K. (2009). Valuing a Wind Farm Construction: a Contingent Valuation Study in Greece. Energy Policy, 37 (5), 1939 - 1944.

Ladenburg, J. (2008). Attitudes Towards On-land and Offshore Wind Power Development in Denmark: Choice of Development Strategy. Renewable Energy, 33 (1), 111 - 118

Lochner, P., Dippenaar, S., Wren, S., Binneman, J., Holland, H., Illgner, P., van Rooyen, C., and Malherbe, F. (2008). Environmental Impact Assessment (EIA) for the Proposed Kouga Wind Energy Project, Jeffreys Bay: Final Environmental Impact Assessment Report. Council for Scientific and Industrial Research.

Mitchell, R., and Carson, R. (1989). Using Surveys to Value Public Goods, Washington, D.C.: Resources for the Future.

O'Hare, M. (1977). Not on My Block You Don't': Facility Siting and the Strategic Importance of Compensation. Public Policy, 25 (4), 407-58.

Studenmond, A. (2006). Using Econometrics: $5^{\text {th }}$ Ed. Pearson: Addison Wesley.

Warren, C.R., Lumsden, C., O'Dowd, S., Birnie, and R.V. (2005). 'Green On Green': Public Perceptions of Wind Power in Scotland and Ireland. Journal of Environmental Planning and Management, 48 (6), 853 - 875.

Yue, C., Liu, C., and Liou, E.M.L. (2001). A Transition Toward a Sustainable Energy Future: Feasibility Assessment and Development Strategies of Wind Power in Taiwan. Energy Policy, 29 (12), 951-963.

Received 31 August 2010; revised 9 September 2011 